\title{
Povos Indígenas no Brasil e a Descolonização da Psicologia
}

\author{
Brisana Índio do Brasil de Macêdo Silva ${ }^{1}$ \\ ${ }^{1}$ Universidade Federal do Delta do Parnaíba, \\ Parnaíba, PI, Brasil.
}

\author{
João Paulo Macedo ${ }^{1}$ \\ ${ }^{1}$ Universidade Federal do Delta do Parnaíba, \\ Parnaíba, PI, Brasil.
}

Resumo: Apesar do incremento de estudos e discussões sobre os povos indígenas no Brasil, a relação da Psicologia, enquanto ciência e profissão, com a temática ainda é pouco abordada nos cursos de graduação e pós-graduação e nas produções acadêmicas. Com o propósito de realizar um balanço sobre a aproximação da produção do conhecimento em Psicologia com a temática indígena, este ensaio buscará apresentar as principais categorias teóricas e analíticas que possam contribuir com o diálogo entre esses dois campos. O método tomou como base a revisão integrativa, em que primeiramente destacamos as principais contribuições teóricas e analíticas acerca da produção acadêmica brasileira sobre os povos indígenas para, em seguida, situarmos a produção científica da Psicologia sobre o tema no Brasil. Ao final, sinalizamos para a importância de se construir um recorte crítico capaz de fortalecer a Psicologia nos estudos sobre os povos indígenas. Também destacamos os estudos pós-coloniais e decoloniais críticos ao eurocentrismo enquanto organizador e regulador da visão de mundo, da história e da concepção de ser humano.

Palavra-chave: Psicologia, Povos Indígenas, Pós-colonial, Decolonial.

\section{Indigenous People in Brazil and the Decolonization of Psychology}

\begin{abstract}
Despite the increase in studies and discussions about indigenous peoples in Brazil, the relationship between psychology, as a science and profession, and the subject is still little addressed in undergraduate/postgraduate courses and academic productions. Aiming to assess the approximation of the production of knowledge in Psychology with the indigenous theme, this essay will present the main theoretical and analytical categories that can contribute to the dialogue between these two fields. To this end, this study comprises an integrative review that both highlights the main theoretical and analytical contributions of the Brazilian literature on indigenous peoples and situates the Brazilian scientific production in Psychology on the theme. This research signals the importance of building a critical cutout capable of strengthening Psychology in studies addressing indigenous peoples, stressing post-colonial and decolonial studies criticizing the role of Eurocentrism as an organizer and regulator of worldview, history, and the conception of the human being.
\end{abstract}

Keywords: Psychology, Indigenous Population, Post-colonial, Decolonial.

\section{Los Pueblos Indígenas en Brasil y la Descolonización de la Psicología}

Resumen: A pesar del aumento de los estudios y debates sobre los pueblos indígenas en Brasil, la relación entre la psicología, como ciencia y profesión, y el tema sigue siendo poco abordado en los cursos de grado y posgrado y en las producciones académicas. Con el propósito de hacer un balance sobre la aproximación de la producción de conocimiento en Psicología 
con el tema indígena, este ensayo se propone presentar las principales categorías teóricas y analíticas que pueden contribuir al diálogo entre estos dos campos. El método se basó en una revisión integradora en la que, en primer lugar, destacamos las principales contribuciones teóricas y analíticas acerca de la producción académica brasileña sobre los pueblos indígenas y, a continuación, situamos la producción científica de la Psicología en Brasil sobre el tema. Al final, señalamos la importancia de construir un recorte crítico capaz de fortalecer la psicología en los estudios sobre los pueblos indígenas. En esta ocasión, destacamos los estudios críticos postcoloniales y decoloniales del eurocentrismo mientras organizador y regulador de la visión del mundo, la historia y la concepción del ser humano.

Palabra clave: Psicología, Pueblos Indígenas, Postcolonial, Decolonial.

\section{Introdução}

Nas últimas quatro décadas, um maior número de grupos indígenas passou a se autodeclarar e a reivindicar o reconhecimento de sua condição étnica e de seus direitos constitucionais, emergindo como novos sujeitos coletivos e políticos na luta pela afirmação, defesa e valorização dos territórios e da cultura indígena no Brasil. Tal fenômeno denominado pela Antropologia de "etnogênese", "(re)emergência étnica", "reetinização", "etnicização", "ressurgimento" ou "viagem de volta", corresponde, para especialistas, ao movimento de constituição de novos grupos étnicos (Arruti, 1997; Oliveira, 1998, 2004). Porém, são denominações que têm recebido críticas de setores do próprio movimento indígena brasileiro, pois sugerem certa espontaneidade e inventividade do processo de (re)afirmação étnica desses grupos. Assim, preferem ser reconhecidos por suas histórias de luta e de resistência, motivo pelo qual renomeiam o fenômeno de processo de indianização e/ou de fortalecimento da indianidade, por compreenderem o processo de (re)afirmação étnica dos grupos indígenas no país enquanto uma prática de (re)existência cultural e política (Santos \& Santos, 2019).

Ademais, o movimento indígena tem denunciado, de forma reiterada, os elementos fundantes da formação social brasileira, marcada por um histórico de opressão, extermínio e invisibilidade dos povos indígenas e demais grupos minoritários, cujo cenário de recrudescimento tem sido intensificado nos últimos anos, com: a) o retorno do debate sobre o marco temporal - com a assinatura do parecer GM-05 pela Advocacia Geral da União (AGU), em julho de 2017 que restringe o direito constitucional de demarcação de terras dos povos indígenas e quilombolas, caso eles não comprovem que a ocupação da terra disputada data de antes da promulgação da Constituição de 1988.
O tema está em pauta no Supremo Tribunal para definição e orientação de casos futuros; b) a aprovação do polêmico Decreto n. ${ }^{\circ}$ 9.142/2017, que abria a Reserva Nacional do Cobre (Renca), na Floresta Amazônica, para exploração por mineradoras, mas que foi revogado posteriormente pelo presidente "ilegítimo" Michel Temer (2016-2018), devido às repercussões internacionais e às mobilizações ambientalistas; c) o desmonte na Fundação Nacional do Índio (Funai), por meio do Decreto n. ${ }^{\circ}$ 9.010/2017, que resultou no fechamento de unidades de Coordenação Técnica Local (CTL) em muitas unidades da federação; e d) a promulgação da Medida Provisória (MP) no 870/2019 pelo atual mandatário "extremista" da nossa República, Jair Bolsonaro (2019-hoje), que transferiu a Funai do Ministério da Justiça para o Ministério da Mulher, Família e Direitos Humanos, e determinou que caberia ao Ministério da Agricultura a função de proteger e demarcar as terras indígenas e dos povos quilombolas. O movimento indígena e aliados rapidamente responderam com a intensificação de mobilizações e denúncias junto ao Congresso Nacional e à comunidade internacional para reverter a votação final da MP. Mesmo com a insistência por parte do Governo Federal que reeditou a matéria com uma segunda Medida Provisória, $\mathrm{n}^{\circ} 886 / 2019$, esta foi definitivamente tornada sem efeito pelo Supremo Tribunal Federal (STF) ao manter a suspensão, por entender que a medida desrespeita os direitos dos povos indígenas assegurados na Constituição Federal de 1988.

Ressalta-se que as medidas perpetradas pelo Governo Federal indicam, de um lado, a obstaculização das demarcações das terras indígenas no Brasil em benefício dos interesses dos ruralistas, mineradores e madeireiros, que, em prol do acúmulo do capital e da expansão do agronegócio, lançam mão de ataques aos povos indígenas e a seus territórios. Por outro lado, 
são medidas que atuam enquanto estratégia de etnocídio e de desindianização com o extermínio sistemático da cultura e tradição indígenas, por meio de sua integração (anexação) à sociedade nacional de forma excludente e violenta (Adoue, 2019).

Diante desse gravíssimo quadro, a Psicologia não pode ficar alheia à causa indígena no Brasil. O processo sócio-histórico de dominação, violência, silenciamento e exclusão dos indígenas, independentemente do governo de plantão, produz marcas indeléveis que comprometem a qualidade de vida, o bem viver e a saúde mental desses povos (Teixeira, 2010). Apesar do incremento de estudos e discussões no âmbito da Psicologia sobre o universo das questões indígenas e dos debates étnico-raciais dos últimos anos, tais temáticas ainda são pouco abordadas na formação graduada e pós-graduada da área. O risco da manutenção desse distanciamento em relação aos povos indígenas no Brasil é o desconhecimento e o silenciamento por parte de nossa ciência e profissão sobre as inúmeras demandas e pautas de reivindicação do movimento indígena, bem como sobre as particularidades culturais e linguística de cada povo e etnia (Conselho Regional de Psicologia de São Paulo [CRP-SP], 2010; 2016; Ferraz \& Domingues, 2016).

Com a inserção de psicólogas(os) nas políticas públicas e com a interiorização da profissão por todo o país, observa-se uma maior presença de profissionais em comunidades e em áreas indígenas de diferentes localidades. Por isso, é de máxima importância potencializar essa aproximação a fim de orientar e realizar a qualificação profissional necessária, no intuito de fortalecer o compromisso ético-político da Psicologia junto aos povos indígenas no Brasil (CRP-SP, 2010; 2016).

Atento a isso, o Sistema Conselhos de Psicologia, por meio de seus documentos técnicos, indica que cabe à(ao) profissional de psicologia garantir o respeito à integridade cultural e étnica dos povos indígenas; apoiar suas lutas e reivindicações pelo direito à terra, à saúde e à educação; valorizar a diversidade étnica e cultural; promover ações de saúde mental com enfoque psicossocial; fortalecer os laços familiares e os vínculos comunitários; proporcionar espaço de debate sobre a temática indígena; fortalecer a participação política; dentre outras (CRP-SP, 2010). No entanto, muitos são os desafios postos, pois abarcam desde aspectos teórico-metodológicos e interventivos, além do permanente diálogo com as cosmovisões e as propostas de desenvolvimento que respeitem e promovam a diversidade sociocultural e a preservação do território e das tradições desses povos.

Como forma de fortalecer esse debate, tomamos a literatura sobre a questão indígena no Brasil e propomos apresentar as principais categorias teóricas e analíticas que possam contribuir no/para o diálogo entre a Psicologia e povos indígenas. Por meio de uma revisão integrativa, localizamos nos estudos sobre os povos indígenas as principais contribuições sobre a temática, para, em seguida, situarmos a produção científica da Psicologia no Brasil a esse respeito. Destacamos ainda no bojo das reflexões propostas a importância de se construir um recorte crítico capaz de fortalecer a Psicologia nos estudos sobre os povos indígenas no Brasil.

\section{Breves considerações sobre as produções discursivas acerca dos indígenas no Brasil}

Estima-se que quando os portugueses aportaram na América, cerca de cinco milhões de pessoas viviam em terras que hoje identificamos como Brasil, distribuídas em 600 etnias diferentes, com organizações sociais, variações linguísticas e cosmovisões próprias. Diante do vasto território e da diversidade de riquezas presentes, os invasores europeus realizaram um violento processo de colonização das terras e dos povos originários que aqui habitavam, por meio de exploração, escravização e ações genocidas, além das estratégias de aculturação e assimilação desses povos. Ademais, a empresa colonizadora deixou marcas profundas no discurso sobre o indígena no Brasil, prefixando pelo menos duas fortes representações no imaginário nacional: "índio aliado/índio inimigo" (B. S. Gonçalves, 2015, p. 37), que se refletiram inclusive nos registros literários como uns dos principais campos de enunciação sobre a construção do discurso colonizador eurocêntrico (Barreto, 2017).

Para o autor, nas obras do chamado Brasil Quinhentista, por exemplo, os indígenas foram representados pela visão dualística do colonizador, dividida entre a imagem do índio selvagem e a do mito do bom selvagem, de Jean-Jacques Rousseau, que caracteriza o indígena como bom, puro e ingênuo, o que justificaria serem colocados como objeto de ação catequética, a exemplo dos escritos de Padre José de Anchieta, Padre Manuel de Nóbrega, Fernão Cardim e Padre Antônio Vieira (Barreto, 2017). No Brasil Colônia 
Seiscentista, os registros literários apresentavam as terras brasileiras como um mundo a ser desbravado, repleto de matas e perigos, onde o desbravador iria domesticar os nativos, doutrinando-os na fé cristã (Barreto, 2017). Alguns textos da época foram inclusive objeto de investigação pela historiografia da Psicologia no Brasil ao tratar sobre a "psicologia" jesuítica e a medicina da alma com suas normas da arte de viver (Massimi, 2001). Já no período Barroco, destacaram-se os relatos, as crônicas e as poesias que reforçavam a subalternidade dos povos indígenas diante do colonizador, por meio das obras de Bento Teixeira, Gregório de Matos, dentre outros (Barreto, 2017).

Somente no período pós-independência foi possível observar uma mudança na representação do indígena com o surgimento do movimento literário nomeado de Romantismo Brasileiro (Barreto, 2017). Em busca de um nacionalismo e de uma "brasilidade", a produção literária do Romantismo Indianista (18361852) colocou o indígena como o grande herói nacional e exaltou a natureza e a pátria com o propósito de criar uma nova identidade nacional. No entanto, autores como Barreto (2017) e B. S. Gonçalves (2015) evidenciam que tais discursos, embora rompam em certa medida com as representações produzidas nos períodos anteriores, ainda são dotados de teor ideológico e colonizador, que se refletia inclusive nas políticas indigenistas do início do século XX.

No campo das representações, destacamos outras imagens que também circularam e ajudaram a modelar o imaginário social sobre o indígena no Brasil. Trata-se da representação social do protótipo do índio xinguano e as dos chamados "índios misturados", também presentes na política indigenista brasileira e na própria produção acadêmica sobre o tema (Oliveira, 1998). Criado em 1910 com o propósito de "civilizar" e "nacionalizar" os indígenas aldeados ou não, o Serviço de Proteção Indígena (SPI) de caráter tutelar e assimilacionista resultou na promoção de violências e etnocídio, por meio de: massacres, assassinatos, chacinas, servidão por dívida, sequestro de crianças, estupros, fome e epidemias. No Nordeste brasileiro, por exemplo, região pouco explorada pela produção acadêmica acerca da presença indígena no país, aldeamentos foram extintos e suas terras incorporadas a propriedades privadas e ao Estado (Oliveira, 2004). Para Arruti (1997), até as décadas de 1950 e 1960, os índios do Nordeste eram retratados sob um viés de decadência, assimilação, aculturação e migração, permanecendo "presos ao diagnóstico básico do iminente desaparecimento, da decadência cultural e da desagregação social" (p. 12). Apenas nos anos 1970, endossa o autor, foi que se abandonou "a categoria identitária de 'índios nordestinos' e os modelos integração e acampesinamento para repensá-la sob os modelos de tradições inventadas e etnicidades" (p. 12).

O período da ditadura civil-militar tem um capítulo à parte nessa história, marcada por atrocidades que incluem a matança de tribos inteiras, práticas de tortura e crueldades diversas cometidas por grandes proprietários de terras e por agentes do Estado. Em decorrência, a partir dos anos 1970 surgiram novas formas de luta e resistência dos povos indígenas frente à política integracionista vigente na época (B. S. Gonçalves, 2015). Para Luciano (2006), foi um período extremamente rico, de vários encontros e assembleias (em níveis local, regional e nacional) que foram importantíssimos para as conquistas dos direitos indígenas consolidados na Constituição Federal de 1988, em meio ao processo de redemocratização do país.

Nessa luta, os povos indígenas reafirmaram-se mais fortemente como sujeitos e protagonistas na arena política brasileira, o que não apenas resultou nas garantias constitucionais conquistadas, como também propiciou novas interpretações e novos temas sobre a questão indígena no país. Porém, a luta perdura frente ao acirramento dos conflitos com ruralistas, mineradores e os interesses do capital nacional e estrangeiro, cujos projetos desenvolvimentistas e integracionistas, ao longo das três últimas décadas, não param de colocar em risco o direito dos indígenas de existirem e afirmarem sua cultura e seu território.

\section{Estudos indígenas no Brasil: contribuições para o debate}

O reconhecimento das identidades étnicas e das práticas culturais, sociais, educacionais e religiosas dos povos indígenas proporcionou o desenvolvimento de pesquisas e produções acadêmicas no país por diversas áreas do conhecimento, com o destaque para a antropologia, a sociologia, a história, a educação, a linguística e a saúde pública.

No campo da educação, a intensificação dos debates sobre os direitos indígenas colaborou para o aumento significativo da produção científica brasileira sobre educação escolar indígena, especialmente 
nas últimas décadas, a partir das novas orientações legais (Luciano, 2006; Maroldi, Lima, \& Hayashi, 2018). A criação de diretrizes específicas sobre educação indígena, a exemplo da Lei n. ${ }^{\circ} 11.645 / 2008$, que instituiu a obrigatoriedade do estudo sobre a história, a cultura e a luta dos negros e dos povos indígenas no Brasil, nas redes de ensino público e privado, foi um importante passo para delinear novos objetos de estudos relacionados à luta pelo direito à escola e por uma educação diferenciada, intercultural, bilíngue ou multilíngue, comunitária, que valorize as formas de organização dos povos indígenas (Maroldi et al., 2018). A maioria dos estudos sobre educação indígena versa sobre o papel da escola no contexto indígena; processos pedagógicos; aspectos linguísticos; oralidade e escrita; educação bilíngue ou multilíngue e intercultural; políticas de educação escolar indígena; processo de escolarização das crianças indígenas; processo de ensino-aprendizado e socialização das crianças indígenas; formação de professores indígenas; presença indígena no ensino superior; políticas afirmativas para os povos indígenas; movimento indígena escolar, dentre outros temas (Luciano, 2006; Maroldi et al., 2018). Trata-se de um vasto campo de estudos, inclusive interdisciplinar, que conta com indígenas como pesquisadores.

A saúde também se destaca com inúmeras produções científicas, especialmente sobre atenção primária em saúde para a população indígena, e com estudos relacionados ao campo de conhecimento da antropologia da saúde e abordagens etnográficas. Para Sandes, Freitas, Souza e Leite (2018), muitos estudos discorrem sobre a saúde da criança, da mulher e do idoso indígena, com enfoque nas principais causas de morbimortalidade, além de investigações em torno do acesso de indígenas aos serviços públicos de saúde; da implantação de políticas públicas à população indígena; da participação indígena na atenção primária à saúde; da formação em saúde indígena; da percepção da atenção à saúde indígena; das noções de corpo nas cosmologias indígenas; das práticas de saúde indígena e os rituais de cura e de iniciação xamânica; e da atuação de profissionais de saúde e dos agentes indígenas de saúde (Coimbra, Santos, \& Cardoso, 2007; Marcolino, 2012; Pérez-Gil, 2001; Reis, Costa, Faro, \& Malosso, 2016; Santos et al., 2018).

No âmbito da saúde mental, há destaque dos estudos sobre o alto consumo de álcool em comunidades indígenas, que ocasiona problemas familiares, sociais e psicológicos, e leva à morte (Branco, Miwa, \& Vargas, 2018). No relatório do Levantamento Nacional sobre Padrões de Consumo de Álcool e Outras Drogas no Brasil, de que participaram onze comunidades indígenas, com o total de 1.455 indígenas, foi constatado que os homens bebem mais do que as mulheres, pois $51,7 \%$ e $24,6 \%$ deles bebem, respectivamente. Por outro lado, as mulheres indígenas apresentam maior proporção de consumo abusivo de álcool, enquanto os homens apresentam maior prevalência de consumo dependente. Em relação a faixa etária, sobressaem aqueles entre 18 a 34 anos (43\%) como os maiores consumidores de álcool nas comunidades pesquisadas, de modo que urge a preocupação com os mais jovens (18 a 24 anos) por serem aqueles que apresentam maior prevalência do consumo dependente de álcool (Duarte, Stempliuk, \& Barroso, 2009).

A problemática do suicídio também é uma preocupação apontada pelos estudos em saúde mental na população indígena. Dados do boletim epidemiológico do Ministério da Saúde (Ministério da Saúde, 2017) apontam que a taxa de mortalidade por suicídio entre os povos indígenas (15,2/100 mil hab.) é quase o triplo da média nacional (5,7/100 mil hab.). Além disso, a maioria das mortes ocorrem na faixa etária de 10 a 19 anos $(44,8 \%)$, portanto, na população mais jovem. Os estudos consideram como fatores importantes para compreender os altos índices do suicídio entre os povos indígenas: a questão fundiária e os conflitos referentes a demarcação de terras; a depredação dos territórios por ações de desmatamento, contaminação por agrotóxicos, atividades ilegais de mineração e abertura de estradas; a violência e assassinatos de lideranças indígenas e demais integrantes das comunidades indígenas; e a omissão do Estado e a falta de assistência de políticas públicas e de segurança às comunidades (Conselho Indigenista Missionário [CIMI], 2016). Esse conjunto de fatores acarreta a falta de perspectivas futuras, a emergência de conflitos identitários e a perda de referências tradicionais, que, nas palavras de Bonilla (2016), são produtores de asfixias e distanciamentos, o que acarreta, a depender da organização e da cosmovisão das etnias, o desgosto, o sofrimento e leva à morte autoprovocada.

Mais recentemente, um compilado de estudos de base etnográfica, organizado por Araúz e Aparício (2017), abordara o suicídio em grupos indígenas de diferentes etnias no Brasil, além de populações 
ameríndias que habitam o Peru, o Equador e a fronteira entre Colômbia e Venezuela, apresentando uma excelente contribuição para o tema ao tirar o fenômeno do âmbito privado e chamar atenção para o fato de que o autoextermínio individual ou coletivo entre indígenas não pode ser reduzido à desintegração cultural ou ao sofrimento existencial. Pelo contrário, a depender da etnia ou do grupo indígena, o fenômeno tem bases cosmopolíticas que configuram o suicídio de modo próprio, ligado a uma complexidade de questões que, além daquilo que já foi relatado anteriormente, também inclui conflitos intergeracionais, conjugais e crises de masculinidade, na forma como os elementos mítico-simbólicos se expressam nas relações cotidianas; ou inclui aspectos relacionados a questões do xamanismo e das práticas de feitiçaria, já que não se separa vivos e mortos; ou corresponde ainda a um modo de denúncia das expressões ou reverberações de atos genocidas contra os povos indígenas. São aspectos que seguramente precisam ser aprofundados à luz do perspectivismo, a partir da relação entre as ontologias ameríndias e a conformação das subjetividades indígenas, certamente atravessadas por subjetividades não necessariamente humanas (Araúz \& Aparício, 2017).

No campo de estudos da antropologia, da história e das ciências sociais, também estão presentes na literatura sobre a questão indígena no Brasil temas como o processo de (re)afirmação étnica indígena ou de (re)existência cultural e política, que descrevem processos sociais e históricos de diversos grupos étnicos, organizados em movimentos sociais, para afirmar identidades coletivas e territorialidades, além de garantir e reivindicar direitos (Arruti, 1997; Oliveira, 1998, 2004). A Convenção n. ${ }^{\circ} 169$ sobre "Povos Indígenas e Tribais em Países Independentes", da Organização Internacional do Trabalho (OIT), de 1989, que estabelece a autoidentificação étnica como critério fundamental para o reconhecimento étnico dos povos indígenas, e que foi ratificada no Brasil por meio do Decreto n. ${ }^{\circ}$ 143/2002, certamente foi um grande avanço para fortalecer o movimento indígena brasileiro. Sem dúvidas, o decreto se tornou recente uma arena de embates que tem permeado o campo dos estudos indígenas no Brasil em função dos impasses quanto à aplicabilidade da Convenção pelas autoridades judiciais e administrativas. Por vezes, o viés formalista e tecnicista da produção de laudos antropológicos para a identificação étnica de tais grupos recai no risco de reproduzir certo modelo de indianidade historicamente construído pelos órgãos indigenistas estatais do Brasil, excluindo outras formas de ser e se se reconhecer indígena. Esse é o caso de muitos grupos étnicos que só mais recentemente passaram a assumir sua identidade indígena em diversos contextos sociais, seja nas cidades (Ferreira Filho, 2017), nas comunidades rurais (Kós, 2015), nas comunidades ribeirinhas (Peixoto, Arenz, \& Figueiredo, 2012), dentre outros.

Para Ferreira Filho (2017), embora a presença indígena no contexto urbano não seja algo recente, os Censos de 1991, 2000 e 2010 indicaram aumento de $333,75 \%$, entre os anos de 1991-2010, de pessoas que se autoidentificam como indígenas em áreas urbanas. Em 2010 o Instituto Brasileiro de Geografia Estatística (IBGE) registrou 817.963 mil pessoas que se autodeclaram indígenas no país, distribuídas em 305 etnias e 274 línguas. Desses, 315.180 mil residem em áreas urbanas. O órgão atribui o crescimento a dois fatores: a) mudança no questionário demográfico a partir do Censo de 1991, que incluiu no quesito cor e raça a opção "indígena"; b) aumento no número de pessoas que se autodeclaram indígenas no país como um todo, diante de uma maior afirmação étnica e cultural dos povos indígenas nas últimas décadas, especialmente na região Nordeste (IBGE, 2012).

Nesse bojo, estudos que tratam sobre organização política, cidadania e direitos indígenas no campo dos direitos sociais e das políticas públicas são frequentes. Discussões sobre a luta pela terra e em defesa do território e da territorialidade indígena, também têm sido uma constante nesses estudos devido: a) aos inúmeros conflitos entre os povos indígenas e ruralistas na luta pela demarcação e posse de terra no país; b) às diversas situações de represálias, ameaças e assassinatos das populações indígenas; c) aos impactos dos projetos desenvolvimentistas (abertura de rodovias e construção hidroelétricas), agrários e fundiários nas comunidades indígenas; d) aos problemas locais e globais relacionados com a degradação do meio ambiente; e, sobretudo, e) em função do conjunto de políticas e medidas legislativas que tramitam no Congresso Nacional, que impactam diretamente os direitos e os modos de vida dos povos indígenas (Alcântara, Tinôco, \& Maia, 2018).

Por fim, destacamos os estudos sobre etnicidade e gênero que tratam de temas como: os direitos sexuais e reprodutivos das mulheres indígenas; violência contra as mulheres indígenas; associações e organizações de 
mulheres indígenas; a participação política de mulheres indígenas; e a necessidade de desenvolvimento de medidas e ações afirmativas voltadas para as mulheres indígenas do Brasil (Segato, 2003).

Certamente não é pretensão nossa esgotar a temática, mas tão somente apresentar quão ampla é a pauta da questão indígena no Brasil e como esta tem permeado os estudos e produções acadêmicas de diversas áreas, até mesmo para sinalizar a importância da produção de conhecimentos contra-hegemônicos e que coloquem em análise as relações de colonialidade que mantêm quadro de desigualdade, perseguição, violência e invisibilidade dos povos indígenas no país.

\section{Construção de um discurso contra-hegemônico, diálogo intercultural e epistemologias pós-coloniais e decoloniais}

A ampliação do debate em torno da temática indígena tem sinalizado para a urgência de se romper com visões generalistas, simplistas e colonizadoras na perspectiva de construir discursos contra-hegemônicos diante das concepções eurocêntricas e coloniais enraizadas em nossa história. Grandes contribuições nesse sentido são oriundas das próprias produções literárias e cinematográficas indígenas, além da produção acadêmica de pesquisadores(as) indígenas, inclusive no âmbito da pós-graduação, que têm chamado para si a tarefa de recompor sua própria história com narrativas que afirmem o lugar de luta e de resistência dos povos indígenas no Brasil (Portela \& Nogueira, 2016).

São produções que têm despertado a sociedade em geral para uma pluralidade de visões de mundo que fundamentam cosmovisões, conhecimentos, culturas e formas de organização social, política e econômica dos povos indígenas. Além disso, observa-se frutíferos diálogos entre o campo do indigenismo brasileiro contemporâneo, os estudos interculturais e o debate pós-colonial e decolonial.

Os estudos interculturais nasceram na Europa e nos EUA, no transcurso do século XX, como resposta aos fenômenos socioculturais, migratórios e oriundos de conflitos étnicos e/ou culturais como práticas xenófobas e racistas. Na América Latina, esse debate se fundamentado nas demandas e reivindicações de minorias étnicas, na perspectiva de trazerem à tona séculos de "subordinação, homogeneização e invisibilização por parte da cultura dominante na busca do respeito, igualdade e legitimidade entre as diferentes comunidades étnico-culturais e frente ao Estado" (Guzmán, 2011, p. 14). Ressalta-se que esses estudos extrapolam o plano cultural, já que "processos de aculturação e assimilação" atravessam tramas que são ao mesmo tempo "cultural, social, política, econômica, epistêmica, ontológica e cosmogônica" (Guzmán, 2011, p. 56). Atentar para tais aspectos é estratégico para a desconstrução da matriz da colonialidade do poder, do saber e do ser, estruturante da nossa formação social e de como o Estado brasileiro tem lidado historicamente com a questão indígena.

Os estudos pós-coloniais surgem na década de 1970, na Ásia e na África, com o propósito de denunciar as diferentes formas de opressão e dominação dos povos colonizados, a fim de entender como se constrói discursivamente o mundo e o homem colonizados a partir do olhar do colonizador. Contam com contribuições de teóricos como: as de Franz Fanon, Edward Said, Stuart Hall, Albert Memmi e Aimé Césaire; as do Grupo de Estudos Subalternos orientado pelos trabalhos de Ranajit Guha e Gayatri Chakrabarty Spivak, por exemplo; além de influências de autores como Michel Foucault, Jacques Derrida, Jean-François Lyotard (Carvalho \& Rosevics, 2017). Quanto aos estudos decoloniais, eles surgem na década de 1990 com a criação do Grupo Modernidade/Colonialidade, no intuito de oferecer (re)leituras sócio-históricas sobre as diferentes formas de opressão e dominação dos povos colonizados latino-americanos. Tal perspectiva defende uma decolonialidade epistêmica, teórica e política das ciências sociais na América Latina no século XXI. Têm como principais autores: Walter Mignolo, Aníbal Quijano, Enrique Dussel, Nelson Maldonado-Torres e Arthuro Escobar, dentre outros (Ballestrin, 2013). Ressalta-se ainda que esse debate tem sido atualizado pelo chamado feminismo decolonial, que aglutina experiências e críticas do movimento de mulheres negras, faveladas, camponeses, indígenas e lésbicas latino-americanas e caribenhas, denunciando o quanto as lógicas e poderes "eurocêntricos, racistas, classistas, misóginos, heterocentrados e coloniais" (Araújo \& Mattos, 2016, p. 22) marcam suas vidas, exploram-nas e tentam negar sua "capacidade de gerir e terem controle sobre suas escolhas e seus corpos" (Araújo \& Mattos, 2016, p. 26). Têm como principais autoras: Breny Mendonza, Catherine Walsh, Gloria Anzaldúa, Luciana Ballestrin, Maria Lugones e Yüderkys Espinosa, dentre outras. 
Em suma, tais perspectivas teóricas e analíticas, em suas diversas expressões, têm tido grande influência nas discussões e estudos indígenas, inclusive dialogando, em alguma medida, com os saberes indígenas, na crítica e no enfrentamento das marcas da colonialidade do poder, do saber e do ser, estruturantes e produtores de violências e ofensivas contra os povos indígenas no Brasil.

Nesse sentido, levando em conta o que temos discutido, cabe refletirmos sobre a aproximação da Psicologia com a temática, considerando que os saberes psicológicos foram fundados com referência no homem burguês e nas características do mundo ocidental moderno/civilizador, permeados pelas relações de colonialidade do poder, do saber e do ser. Assim, questionamos: Como a Psicologia tem abordado o tema? A Psicologia tem buscado construir um discurso contra-hegemônico em relação à base epistêmica eurocêntrica? Tem possibilitado que os povos indígenas narrem e contem suas próprias histórias?

\section{Psicologia e povos indígenas: desafios e interpelações}

Como marco de aproximação da Psicologia, por meio de suas entidades, com a temática dos povos indígenas, destacamos o Seminário Nacional "Subjetividade e Povos Indígenas" realizado em 2004, em Brasília, pelo Conselho Federal de Psicologia (CFP) com o Conselho Indigenista Missionário (CIMI), no intuito de discutir sobre a atuação da(o) psicóloga(o) junto a esses povos (CRP-SP, 2010). Após a realização desse Seminário, o Conselho Regional de Psicologia de São Paulo criou o Grupo de Trabalho (GT) "Psicologia e Povos Indígenas", que, desde então, procurou: a) desenvolver ações, atividades e encontros que viabilizassem o diálogo interdisciplinar entre psicólogas(os), lideranças indígenas e demais profissionais de áreas afins (saúde, antropologia, historiadores, assistentes sociais, educadores); b) estabelecer parcerias com demais entidades e instituições ligadas à temática; e c) elaborar referências para a atuação dos psicólogos (CRP-SP, 2010). Os relatos desses encontros foram publicados, em 2010, no livro "Psicologia e Povos Indígenas" (CRP-SP, 2010), e, em 2016, para marcar uma década de atuação do GT Psicologia e Povos Indígenas, foi publicado o livro "Povos indígenas e Psicologia: a procura do bem viver", resultado das palestras proferidas no $3^{\circ}$ Ciclo de Debates "Psicologia e Povos Indígenas”, realizado na USP, nos campi de São Paulo, Ribeirão Preto e Santos (CRP-SP, 2016).
O acúmulo dessas discussões indicaram desafios à Psicologia, enquanto ciência e profissão, diante das questões indígenas: o desconhecimento das populações indígenas quanto à atuação do(a) psicólogo(a); a complexidade das relações interculturais dos grupos indígenas (cosmovisões, traços culturais, dimensão mítico-simbólica) e a diversidade linguística dos grupos étnicos; a falta de articulação entre as instâncias governamentais, como também entre profissionais de saúde; e a falta de infraestrutura dos órgãos de proteção e a precarização de seus serviços (CRP-SP, 2010, 2016).

Quanto ao estado da arte das produções acadêmicas (teses, dissertações, monografia e relatórios científicos) em Psicologia sobre a temática indígena, Vitale e Grubits (2009) sinalizaram que os primeiros trabalhos desenvolvidos datam de 1980 e apontam que somente a partir da década de 1990 houve um maior interesse da Psicologia na temática, que se tornou mais significativa a partir dos anos 2000, perfazendo um total de 49 produções entre 1980 e 2009. Os temas abrangeram estudos sobre mito e mitologia indígenas; jogos e brincadeiras infantis (como faz de conta); aspectos relacionados à saúde da população indígena; relações familiares e afetivas; suicídio; AIDS; álcool e outras drogas; e aspectos educacionais, religiosidade e tradições culturais.

Mais recentemente, Ferraz e Domingues (2016) realizaram levantamento da literatura sobre os povos indígenas na Psicologia brasileira tomando como referência o estudo desenvolvido por Vitale e Grubits (2009). No entanto, ao invés de selecionarem teses, dissertações, monografia e relatórios científicos, as autoras se detiveram na busca de artigos científicos publicados nas bases de dados SciELO e PePSIC, que totalizavam 25 artigos até 2013. Os artigos abordaram temas como: a) a construção da identidade de crianças indígenas; b) os motivos que levam indígenas ao suicídio; c) o modo como a infância é vivenciada na cultura indígena; d) etnoeducação; e) contribuição da Psicologia para a educação indígena; f) comparação entre grupos indígenas e não indígenas acerca de sua cognição visual, motora e verbal; g) representação social sobre o índio na cidade e nos veículos de mídia, bem como entre os profissionais de saúde; h) consumo de álcool entre os indígenas; i) práticas de saúde e cuidado entre os indígenas e os profissionais de saúde; j) participação política da mulher nas comunidades indígenas; e l) contexto de luta pela posse de terras de uma comunidade indígena (Ferraz \& Domingues, 2016). 
A fim de atualizar a produção existente sobre a temática, realizamos a busca nas mesmas bases de dados (SciELO e PePSIC), utilizando os mesmos descritores usados por Ferraz e Domingues (2016): indígena/ índio e psicologia. Localizamos 30 novos artigos publicados entre os anos de 2014 e 2020, que versaram sobre: a) o desenvolvimento cognitivo e sociocultural dos povos indígenas, em seus mais diversos contextos socioculturais e fases do ciclo da vida (Almeida, Pedroso, Magalhães, \& Aido, 2018; Marques, Sousa, Vizzotto, \& Bonfim, 2015; Menezes, Cruz, Corrêa, \& Brito, 2014; Travassos \& Ceccarelli, 2016); b) os aspectos místicos das culturas indígenas (Simão \& Rios, 2016); c) o papel e o desenvolvimento de uma clínica etnopsicológica e transcultural (Bairrão, 2017; Domingues, Honda, \& Reis, 2019; Scorsolini-Comin, 2017); d) as concepções, saberes e práticas de saúde e de saúde mental (Batista \& Zanello, 2016; Berni, 2017; Cuervo, Radke, \& Riegel, 2015); e) o comportamento suicida na população indígena (Staliano, Mondardo, \& Lopes, 2019); f) o uso de bebidas alcóolicas pelos indígenas (Souza, Oliveira, \& Teodoro, 2019); g) as questões identitárias e culturais frente ao acesso a serviços de cunho social, de saúde e/ou de educação escolar indígena (Calegare, 2014; Calegare \& Higuchi, 2016; Delmondez \& Pulino, 2014); h) as representações sociais, crenças coletivas e práticas discursivas acerca dos povos indígenas (Lima, Faro, \& Santos, 2016; Sant'Anna, Castro, \& Jacó-Vilela, 2018, 2019); i) as violências contra os povos indígenas (B. S. Gonçalves, 2017); j) a produção de subjetividade e de estratégias de luta ou resistência no movimento indígena (Farias \& Hennigen, 2019); l) mulheres indígenas, gênero e política (Dutra \& Mayorga, 2019); m) os sentidos, vivências e reposicionamento subjetivo de estudantes indígenas a partir da experiência universitária e da prática docente (Ferreira \& Souza, 2016; Godoy, 2017; Hur, Couto, \& Nascimento, 2018; Ressurreição \& Sampaio, 2017; Viana \& Maheirie, 2017) e n) apontamentos para o posicionamento e a atuação da Psicologia com povos indígenas (Faria \& Martins, 2020; Grubits \& Sordi, 2017; Guimarães, Lima Neto, Soares, Santos, \& Carvalho, 2019).

Diante do exposto, destacamos a importância do incremento da produção acadêmica da Psicologia sobre a questão indígena, produção que seja sensível a um campo amplo de discussões e sintonizada com ele, além de posicionada ético-politicamente como uma aliada na luta pela defesa dos direitos dos povos indígenas. Porém, ressaltamos que essa aproximação precisa vir acompanhada da crítica e da transformação da própria Psicologia, considerando a forte influência da racionalidade eurocêntrica e seu projeto civilizatório violento, reforçado pelo pragmatismo americano funcionalista, que tanto orientou (e ainda orienta) o arsenal teórico e interventivo da nossa ciência e profissão. Autores como Alves e Delmondez (2015) e Faria e Martins (2020) sinalizam o quanto as discussões pós-coloniais e decoloniais podem contribuir para um repensar da Psicologia brasileira, principalmente quanto à tarefa de continuarmos a desacomodar nossa ciência e profissão do afã moderno de classificar, ordenar, disciplinar, controlar, gerenciar e corrigir comportamentos, além de deslocá-la de sua dependência intelectual e engajamento a epistemologias que reforçam o lugar do colonizador. Isso porque o entendimento de que há um modelo de ser humano ideal, homem branco, cristão, heterossexual, cis-gênero, dotado de civilidade e racionalidade, e que se coloca como trabalhador e empreendedor, marca a origem da Psicologia, bem como a das Ciências Humanas. Ademais, tal imagem forjou seu oposto, o não branco e não civilizado, que cabe ser ajustado e aproximado do modelo ideal em sua forma de representar, dizer e viver o mundo.

Para Quijano (2002), a modernidade e o colonial são duas faces da mesma moeda, na medida em que o processo de dominação colonial não findou com a emancipação das colônias pelo mundo. Pelo contrário, na compreensão de Maldonado-Torres (2018), a colonialidade corresponde a uma “. . . lógica global de desumanização que é capaz de existir até mesmo na ausência de colônias formais" (p. 36). Assim, atualiza relações de poder, por meio de mecanismos sofisticados de controle, disciplina, subordinação, subalternização, dominação e exploração, de forma a incidir nos modos de vida dos sujeitos, nas culturas, nas epistemologias, nas crenças e nos valores, colocando-os em lugar de inferioridade a partir de diferenças e hierarquizações étnicas, raciais, de gênero e de classe, dentre outras (Quijano, 2002).

Maldonado-Torres (2018) expõe que tais mecanismos podem ser colocados em análise a partir da colonialidade do poder, do saber e do ser. Porém, como alertam Castro-Gómez e Grosfoguel (2005), são dimensões que não devem ser entendidas apenas por lentes macrossociológicas e por segmentações hierárquicas em que uma é desdobramento da outra, pois coexistem uma na outra. Desse modo, 
recuperamos as indicações de Quijano (2005) sobre a colonialidade do poder enquanto estrutura de dominação da natureza, dos territórios e dos povos, imposta pela ordem capitalista, em que a organização do trabalho é estabelecida segundo a hierarquização étnico-racial, de forma que abrange a servidão, a escravidão e as formas históricas da relação capital-trabalho assalariado e de semisservidão. Esse novo padrão de poder, que tomou a América Latina como laboratório e o exportou para a África e a Ásia, adentrou em outras dimensões da vida social, produzindo, por um lado, novos dualismos com raças consideradas "inferiores" e passíveis de serem "exploradas" e "descartadas", a exemplo de negros, indígenas, asiáticos etc.; e, por outro, gerando reclassificações e processos de reidentificação histórica a partir de mecanismos de homogeneização colonial e cultural, como a prática de etnocídio e a imposição de uma ideologia de democracia racial, assim como ocorreu no Brasil.

A colonialidade do saber segue a mesma matriz moderno/colonial, atualizada no dualismo centro/ periferia, que se impõe a partir "legado epistemológico do eurocentrismo" (Porto-Gonçalves, 2005, p. 3) enquanto parâmetro normativo de produção do conhecimento e estabelecimento de regimes de verdade, padrões de linguagem e definição de quem pode exercer o lugar do sujeito do conhecimento (Maldonado-Torres, 2018). Tais normalizações tentam impor àqueles que foram posicionados como "periféricos" ou "subalternos" que são incapazes e sem legitimidade de compreender o próprio mundo em que vivem a partir das "epistemes que lhes são próprias" (Porto-Gonçalves, 2005, p. 3).

Por fim, Mignolo (2003), inspirado na analítica foucaultiana de poder-verdade-sujeito, entende que a colonialidade do poder e a do saber engendram a colonialidade do ser, no sentido de que configuram e condicionam a experiência do sujeito colonizado no mundo. Por isso, Maldonado-Torres (2007) e Mignolo (2017) alertam quanto à urgência do desmonte do funcionamento dessa complexa matriz, considerando que as colonialidades estão conectadas, gerando, reproduzindo, modificando e mantendo hierarquias interconectadas.

Embora a Psicologia no Brasil e na América Latina já venha desenvolvendo críticas, desde os idos dos anos 1960, em relação à importação teórica-metodológica de conhecimentos descontextualizados, bem como acerca dos processos históricos de violência e opressão das classes populares e das minorias sociais do país, com a Psicologia social-comunitária e as chamadas Psicologias Críticas (diálogos entre psicanálise, marxismo, teoria crítica, construcionismo social, psicologia histórico-cultural, psicologia da libertação, estudos foucaultianos e críticas pós-modernas e pós-estruturalistas e estudos de gênero), é preciso estar atento para evitar a reprodução de certos colonialismos epistêmicos (CFP, 2019). É nesse sentido que mais recentemente têm surgido movimentos de descolonização da Psicologia, com diálogos importantes com os campos de estudos anteriormente referidos, a exemplo da proposta de uma psicologia preta (Veiga, 2019) ou de uma africanização da psicologia (Nogueira, 2019), ou ainda de enegrecimento da psicologia (Santos, 2019); de uma psicologia favelada (M. A. Gonçalves, 2019); e de uma psicologia descolonizada (Adams, Gómez, Kurti, Molina, \& Dobles, 2017; B. S. Gonçalves, 2019; Nogueira, 2019). São produções que, além de oferecerem uma crítica ao eurocentrismo, valorizam as fronteiras e as pluralidades epistemológicas e cosmovisões, na medida em que se atentam às experiências e às tradições que foram "espremidas entre as línguas imperiais" (Mignolo, 2017, p. 12). Nesse sentido, o autor ainda complementa que, enquanto "línguas e categorias de pensamento negadas e expulsas da casa do conhecimento imperial", são, na verdade, grandes inspirações de como "pensar e agir descolonialmente" (Mignolo, 2017, p. 14).

Na mesma esteira, Faria e Martins (2020) apontam que para descolonizar a Psicologia devemos "desobedecer a cartilha colonizadora e posicionar-se contra ela” (p. 33). Assim, de acordo com os autores, é urgente "colaborar para emergência e reorganização das subjetividades e cosmologias ainda colonizadas" (Faria \& Martins, 2020, p. 33).

Como princípio fundante dessa programática, sugere-se que é imprescindível reconhecer que por serem testemunhas, na alma e no corpo, do histórico de violências e silenciamentos que marcaram suas vidas ontem e hoje, as vozes e as presenças dos povos indígenas e demais povos tradicionais são insubstituíveis e irrepresentáveis (Danner, Dorico, \& Danner, 2020). Por outro lado, as formas de enfrentamento dos colonialismos e violações dos direitos desses povos se dão pela "visibilização" e "publicização de suas experiências", pela "enunciação autoral de suas próprias vozes" e "pela politização da própria condição" 
(Danner et al., 2020, p. 71). Portanto, cabe à Psicologia, enquanto aliada, investir na produção de conhecimento que firme posição e que dialogue com esses povos no rompimento do histórico das práticas de "silenciamento, invisibilização e o privatismo, aos quais foram empurrados ao longo da colonização" e dos colonialismos que os perseguem, no passado e no presente (Danner et al., 2020, p. 68).

Ainda como parte dessa programática, neste exercício, cabe desvelar as constantes atualizações das lógicas coloniais que se apresentam a partir de uma teia complexa de hierarquizações raciais, patriarcais, de gênero e sexualidade, de classe, de credo, estéticas, linguísticas, dentre outras, que se produzem sobre os povos indígenas e demais povos tradicionais, sob o julgo do colonialismo do poder, do saber e do ser.

Para isso, precisamos estar sensíveis, atentos e abertos às narrativas e necessidades dos povos indígenas, além de seus campos de força e de luta em seus mais diversos contextos e épocas. Tal aproximação certamente fortalecerá mais ainda novas frentes e agendas de pesquisas para a Psicologia junto à população indígena, tomando como base os estudos latino-americanos sobre povos indígenas e os debates e pautas de reivindicação dos encontros promovidos pela Articulação dos Povos Indígenas do Brasil (APIB) e organizações indígenas regionais. Os temas que têm permeado a agenda do movimento indígena no Brasil e na América latina são: a) memória e história indígena; b) oralidade e tradição oral; c) preservação e fortalecimento das línguas indígenas; d) processos de autoria indígena, literatura indígena e cinema e audiovisual indígenas; e) construção do discurso contra-hegemônico e de diálogos interculturais; f) controle social e políticas públicas; g) associações e organizações indígenas; $h$ ) participação e representação política indígena; i) ambiente e sustentabilidade; j) conflitos agrários e territoriais; k) educação, interculturalidade e saberes tradicionais; l) acesso e permanência dos povos indígenas no ensino superior, bem como alternativas pedagógicas para a educação indígena; m) seguridade alimentar, saúde e povos indígenas; n) saberes/práticas indígenas de cura; o) gênero e etnicidade; p) turismo indígena, projetos comunitários e economia alternativa; e q) problemas sociais indígenas em contextos urbanos.

\section{Considerações finais}

Com o propósito de realizar um balanço sobre a aproximação da Psicologia com a temática indígena, este ensaio buscou apresentar as principais categorias teóricas e analíticas que possam contribuir para o aprofundamento do diálogo entre esses dois campos. Pelo exposto, observamos quão ampla é a pauta da questão indígena no Brasil, que perpassa estudos e produções acadêmicas que versam, em sua maioria, sobre: educação indígena, saúde indígena, suicídio, uso de álcool e outras drogas, organização política, cidadania, direitos indígenas e territorialidade, dentre outros temas.

Nesse bojo, gostaríamos de destacar o incremento das discussões e da produção acadêmica relacionada aos povos indígenas na Psicologia, principalmente nos últimos anos. Isso é fruto, em grande medida, da expansão da atuação de psicólogas(os) junto às comunidades e áreas indígenas, ocasionada, sobretudo, em função de uma maior inserção profissional nas políticas públicas e sociais, devido ao processo de interiorização da profissão e dos cursos de graduação e pós-graduação em Psicologia em todo país.

Apesar da diversidade de temáticas, de realidades e de fenômenos discutidos pela e na Psicologia, que tratam, em grande parte, de temas relacionados ao desenvolvimento cognitivo e sociocultural dos povos indígenas, sobretudo da fase da infância e da adolescência; aos aspectos místicos das culturas indígenas; às práticas e cuidado em saúde, rituais de cura e de iniciação xamânica; ao uso do álcool e outras drogas e ao suicídio; aos aspectos identitários e culturais; à representação social do ser índio; e aos aspectos educacionais dos povos indígenas, dentre outros. Cabe destacarmos que a Psicologia ainda precisa fortalecer novas frentes e agenda de pesquisas junto à população indígena, a exemplo de estudos relacionados ao protagonismo indígena; aos direitos indígenas; ao acesso a políticas públicas; ao direito à terra; aos modos de vida e de subjetivação; às práticas xamânicas e de cura indígena; às cosmovisões e à interculturalidade; e à territorialidade.

Além disso, é urgente que se construa um recorte crítico capaz de fortalecer a Psicologia nos estudos sobre os povos indígenas no Brasil a partir do diálogo com os estudos interculturais e os estudos pós coloniais e decoloniais, para estabelecer pontes com as múltiplas realidades e os campos de resistência e de (re)existência cultural e política que permeiam a luta dos povos indígenas no Brasil. Do mesmo modo, cabe investir em ações de descolonização da Psicologia, ancorada no respeito aos processos de autonomização, às crenças, à cultura, às tradições e às lutas dos povos indígenas, sob uma perspectiva ética, crítica, política e horizontalizada. 


\section{Referências}

Adams, G., Gómez, L. O., Kurti, T., Molina, L.E., \&Dobles, I. (2017). Notes on decolonizing psychology: from oneSpecial Issue to another. South African Journal of Psychology, 47(4), 531-541. https://doi.org/10.1177/0081246317738173

Adoue, S. B. (2019). Os ataques contra os povos indígenas e o novo padrão de dominação. Blog da Boitempo. https:// blogdaboitempo.com.br/2019/01/11/os-ataques-contra-os-povosindigenas-e-o-novo-padrao-de-dominacao/

Alcântara, G. K., Tinôco, L. N., \& Maia, L. M. (Orgs.). (2018). Índios, Direitos Originários e Territorialidade. Associação Nacional dos Procuradores da República. https://www.anpr.org.br/images/2020/Livros/Indios_direitos_ originarios_e_territorialidade.pdf

Almeida, M. D., Pedroso, J. S., Magalhães, C. M. C., \& Aido, E. M. F. (2018). Contexto físico e sociocultural de uma aldeia indígena "Tembé" na Amazônia brasileira. Revista Subjetividades, 18(2), 93-104. https://doi.org/ 10.5020/23590777.rs.v18i2.7113

Alves, C. B., \& Delmondez, P. (2015). Contribuições do pensamento decolonial à psicologia política. Revista Psicologia Política, 15(34), 647-661.

Araújo, F. P., \& Mattos, M. F. (2016). Descolonizar os feminismos Latino americanos e caribenhos: uma perspectiva decolonial das teorias sobre gênero, sexualidade e raça. Revista Três Pontos, 13(1), 21-26.

Araúz, L. C., \& Aparicio, M. (Coords.). (2017). Etnografías del suicidio en América del Sur. Abya-Yala.

Arruti, J. M. A. (1997). A emergência dos "remanescentes": notas para o diálogo entre indígenas e quilombolas. Mana, 3(2), 7-38. https://doi.org/10.1590/S0104-93131997000200001

Bairrão, J. F. M. H. (2017). Protagonismo epistêmico dos povos indígenas: o papel da etnopsicología. Psicologia para América Latina, (spe), 53-62.

Ballestrin, L. (2013). América Latina e o giro decolonial. Revista brasileira de ciência política, 11, 89-117. https:// doi.org/10.1590/S0103-33522013000200004

Barreto, M. R. (2017). Índios de Papel - Construção discursiva do preconceito sobre o indígena no Brasil. Brasiliana: Journal for Brazilian Studies, 5(1), 9-32.

Batista, M. Q., \& Zanello, V. (2016). Saúde mental em contextos indígenas: Escassez de pesquisas brasileiras, invisibilidade das diferenças. Estudos de Psicologia, 21 (4), 403-414. https://doi.org/10.5935/1678-4669.20160039

Berni, L. E. V. (2017). Psicologia e saúde mental indígena: Um panorama para construção de políticas públicas. Psicologia para América Latina, (spe), 64-81.

Bonilla, O. (2016). Desgosto. Revista DR, 3. http://revistadr.com.br/posts/desgosto/

Branco, F. M. F. C., Miwa, M. J., \& de Vargas, D. (2018). Consumo de álcool em comunidades indígenas brasileiras: uma revisão literária. Enfermagem em Foco, 9(3), 8-12. https:// doi.org/10.21675/2357-707X.2018.v9.n3.1124

Calegare, M. G. A. (2014). Estratégias de mudança identitária para acesso a bens e serviços sociais na Amazônia. Revista Psicologia Política, 14(29), 151-169.

Calegare, M. G. A., \& Higuchi, M. I. G. (2016). Transformações das Identidades Coletivas em Comunidade no Alto Solimões/AM. Psicologia: Teoria e Pesquisa, 32(3),1-9. https://doi.org/10.1590/0102-3772e323222

Castro-Gómez, S., \& Grosfoguel, R. (2005). Ciências sociais, violência epistêmica e o problema da invenção do outro. In E. Lander (Org.), A colonialidade do saber: Eurocentrismo e ciências sociais. Perspectivas latino-americanas (pp. 80-87). CLACSO.

Coimbra Jr., C. E. A., Santos, R. V., \& Cardoso, A. M. (2007). Processo saúde-doença. In D. C. Barros, D. O. Silva \& S. A. Gugelmin (Orgs.), Vigilância alimentar e nutricional para a saúde Indígena (pp. 47-74). Editora FIOCRUZ. https://doi.org/10.7476/9788575415870.004

Conselho Indigenista Missionário. (2016). Relatório Violência contra os povos indígenas no Brasil: Dados de 2016. https://cimi.org.br/pub/relatorio/Relatorio-violencia-contra-povos-indigenas_2016-Cimi.pdf

Conselho Federal de Psicologia. (2019). Referências Técnicas para atuação de psicólogas(os) com povos tradicionais. https://site.cfp.org.br/wp-content/uploads/2019/12/CFP_PovosTradicionais_web.pdf

Conselho Regional de Psicologia de São Paulo. (2010). Psicologia e Povos indígenas. http://www.crpsp.org.br/ povos/povos/livro.pdf 
Conselho Regional de Psicologia de São Paulo. (2016). Povos indígenas e Psicologia: A procura do bem viver. https://www.crpsp.org/uploads/impresso/110/RLAg_HX8E6bm0fVjb2gpqCkreIBkTy0W.pdf

Cuervo, M. R. M., Radke, M. B., \& Riegel, E. M. (2015). PET-Redes de atenção à saúde indígena: além dos muros da universidade, uma reflexão sobre saberes e práticas em saúde. Interface - Comunicação, Saúde, Educação, 19, 953-963. https:// doi.org/10.1590/1807-57622014.1364

Danner, L. F., Dorrico, J., \& Danner, F. (2020). Decolonialidade, lugar de fala e voz-práxis estético-literária: reflexões desde a literatura indígena brasileira. Alea: Estudos Neolatinos, 22(1), 59-74. https://doi.org/ $10.1590 / 1517-106 x / 20202215974$

Delmondez, P., \& Pulino, L. H. C. Z. (2014). Sobre identidade e diferença no contexto da educação escolar indígena. Psicologia \& Sociedade, 26(3), 632-641. https:// doi.org/10.1590/S0102-71822014000300012

Domingues, E., Honda, H., \& Reis, J. G. D. (2019). A etnopsicanálise de Devereux no filme Jimmy P.: uma introdução à clínica transcultural. Psicologia em Estudo, 24, 1-15. https://doi.org/10.4025/psicolestud.v24i0.38337

Duarte, P. C. A. V., Stempliuk, V. A., \& Barroso, L. P. (Orgs.). (2009). Relatório brasileiro sobre drogas. Secretaria Nacional de Políticas sobre Drogas. http://www.escs.edu.br/arquivos/DrogasResumoExecutivo.pdf

Dutra, J. C. D. O., \& Mayorga, C. (2019). Mulheres Indígenas em Movimentos: Possíveis Articulações entre Gênero e Política. Psicologia: Ciência e Profissão, 39(n.esp), 113-129. https://doi.org/10.1590/1982-3703003221693

Farias, J. M., \& Hennigen, I. (2019). A Tekoá Ka'aguy Porã: Espaço Ancestral e Produção de Subjetividade Mbya-Guarani. Psicologia: Ciência e Profissão, 39(n.esp), 53-66. https:// doi.org/10.1590/1982-3703003221659

Faria, L. L., \& Martins, C. P. (2020). Fronteiras coloniais, Psicologia da Libertação e a desobediência indígena. Psicologia para América Latina, (33), 33-42.

Ferraz, I. T., \& Domingues, E. (2016). A Psicologia Brasileira e os Povos Indígenas: Atualização do Estado da Arte. Psicologia: Ciência e Profissão, 36(3), 682-695. https://doi.org/10.1590/1982-3703001622014

Ferreira Filho, A. J., (2017). Da invenção do índio nacional às atuais formas de protagonismos indígenas no Brasil. Crítica e Sociedade: revista de cultura política, 7(1), 173-200. https:// doi.org/10.14393/RCS-v7n1-2017-39260

Ferreira,Á.L.M.C.M,\&Souza,V.L.T. (2016).Ossentidos da docênciaparaestudantesdomagistérioindígena:opapelda língua como mediação. Estudos de Psicologia, 33(2), 303-312. https://doi.org/10.1590/1982-02752016000200012

Godoy, D. B. O. A. (2017). O método psicanalítico: pesquisas e populações indígenas. Psicologia para América Latina, (n.spe), 6-22.

Gonçalves, B. S. (2015). Nem tupi nem tapuia. Livre determinação e políticas sociais na trajetória histórica dos indígenas brasileiros. In H. V. Martins, M. R. V. Garcia, M. A. Torres \& D. K. Santos (Orgs.), Intersecções em Psicologia Social: raça/etnia, gênero, sexualidades (pp. 32-55). ABRAPSO Editora. https://repositorio.ufsc.br/bitstream/ handle/123456789/135378/Intersec\%c3\%a7\%c3\%b5es\%20em\%20Psi\%20Social.pdf?sequence=1\&isAllowed=y

Gonçalves, B. S. (2017). Parecer Psicossocial da Violência contra os Povos Indígenas Brasileiros: o Caso Reformatório Krenak. Psicologia: Ciência e Profissão, 37(n.spe), 186-196. https://doi.org/10.1590/1982-3703140002017

Gonçalves, B. S. (2019). Nos caminhos da dupla consciência: América Latina, Psicologia e Descolonização. Editora do autor.

Gonçalves, M. A. (2019). Psicologia Favelada: Ensaios sobre a construção de uma perspectiva popular em Psicologia. Mórula Editorial.

Grubits, S., \& Sordi, A. (2017). Pesquisas nas comunidades indígenas: relações de justiça e igualdade. Boletim Academia Paulista de Psicologia, 37(92), 11-23.

Guimarães, D. S., Lima Neto, D. M. Soares, L. M., Santos, P. D. D., \& Carvalho, T. S. (2019). Temporalidade e corpo numa proposta de formação do psicólogo para o trabalho com povos indígenas. Psicologia: Ciência e Profissão, 39(n.spe), 147-158. https://doi.org/10.1590/1982-3703003221929

Guzmán, B. A. R. (2011). Colonialidade, Interculturalidade e Educação: Desdobramento na relação do Povo Mapuche e o Estado do Chile [Dissertação de mestrado, Programa de Pós-graduação em Educação, Universidade Federal de Santa Catarina]. Repositório Institucional da UFSC. https://repositorio.ufsc.br/xmlui/handle/123456789/94931

Hur, D. U., Couto, M. L. B. S., \& Nascimento, J. S. (2018). Estudantes indígenas na Universidade: uma sessão de grupo operativo. Vínculo, 15(2), 99-119. 
Instituto Brasileiro de Geografia e Estatística. (2012). Os indígenas no Censo Demográfico 2010: primeiras considerações com base no quesito cor ou raça. https://www.ibge.gov.br/indigenas/indigena_censo2010.pdf

Kós, C. V. N. M. (2015). Etnias, fluxos e fronteiras: processo de emergência étnica dos Kariri no Piauí [Dissertação de Mestrado, Programa de pós-graduação em Antropologia, Universidade Federal do Piauí]. Repositório Institucional da UFPI.

Lima, M. E. O., Faro, A., \& Santos, M. R. (2016). A desumanização presente nos estereótipos de Índios e Ciganos. Psicologia: Teoria e Pesquisa, 32(1), 219-228. https://doi.org/10.1590/0102-37722016012053219228

Luciano, G. D. S. (2006). O índio brasileiro: o que você precisa saber sobre os povos indígenas no Brasil de hoje. Secretaria de Educação Continuada, Alfabetização e Diversidade; LACED/Museu Nacional. http://www.educadores.diaadia.pr.gov.br/arquivos/File/pdf/indio_brasileiro.pdf

Nogueira, S. G. (2019). Libertação, descolonização e africanização da psicologia: Breve introdução à psicologia africana. EdUFSCar.

Maldonado-Torres, N. (2007). Sobre la colonialidad del ser: contribuciones al desarrollo de un concepto. In S. Castro-Gómez \& R. Grosfoguel (Coords.), El giro decolonial: reflexiones para uma diversidad epistêmica más allá del capitalismo global (pp. 127-168). Siglo del Hombre Editores.

Maldonado-Torres, N. (2018). Analítica da colonialidade e da decolonialidade: algumas dimensões básicas. In J. Bernardino-Costa, N. Maldonado-Torres \& R. Grosfoguel (Orgs.), Decolonialidade e pensamento afrodiapórico (pp. 27-54). Autêntica.

Marcolino, D. L. (2012). Saúde das Mulheres Indígenas no Brasil [Trabalho de conclusão de curso de graduação, Curso de Enfermagem, Universidade Federal do Rio Grande do Sul]. Repositório Digital LUME. https://lume.ufrgs.br/handle/10183/55289

Marques, F. D., Sousa, L. M., Vizzotto, M. M., \& Bonfim, T. E. (2015). A vivência dos mais velhos em uma comunidade indígenaGuaraniMbyá.Psicologia\&Sociedade,27(2),415-427.https://doi.org/10.1590/1807-03102015v27n2p415

Maroldi, A. M., Lima, L. F. M., \& Hayashi, M. C. P. I. (2018). A produção científica sobre educação indígena no Brasil: uma revisão narrativa. Revista Ibero-Americana de Estudos em Educação, 13(4), 931-952. https://doi.org/ 10.21723/riaee.v13.n3.2018.10211

Massimi, M. (2001). A Psicologia dos jesuítas: Uma contribuição à história das ideias psicológicas. Psicologia: Reflexão e crítica, 14(3), 625-633. https://doi.org/10.1590/S0102-79722001000300018

Menezes, A. B. C., Cruz, M. M. S., Corrêa, H. V.V., \& Brito, R. (2014). Perception and development of Theory of Mind Reasoning in Asurini children, from Amazonia, Brazil. Revista de Etologia, 13(2), 30-37.

Mignolo, W. D. (2003). Histórias locais/projetos globais: colonialidade, saberes subalternos e pensamento liminar. Editora UFMG.

Mignolo, W. D. (2017). Colonialidade: o lado mais escuro da modernidade. Revista Brasileira de Ciências Sociais, 32(94). https://doi.org/10.17666/329402/2017

Ministério da Saúde. (2017). Suicídio, saber, agir e prevenir. Boletim Epidemiológico, 48(30). Secretaria de Vigilância em Saúde. https://portalarquivos2.saude.gov.br/images/pdf/2017/setembro/21/2017-025-Perfilepidemiologico-das-tentativas-e-obitos-por-suicidio-no-Brasil-e-a-rede-de-atencao-a-saude.pdf

Oliveira, J. P. (1998). Uma etnologia dos “índios misturados”? Situação colonial, territorialização e fluxos culturais. Mana, 4(1), 47-77. https:// doi.org/10.1590/S0104-93131998000100003

Oliveira, J. P. (Org.). (2004). A viagem da volta: etnicidade, política e reelaboração cultural no Nordeste indígena (2a ed.). Contra Capa. http://jpoantropologia.com.br/pt/wp-content/uploads/2021/03/JPOL_A_Viagem_da_ Volta_Completo_compressed.pdf

Peixoto, R. C., Arenz, K., \& Figueiredo, K. (2012). O Movimento Indígena no Baixo Tapajós: etnogênese, território, Estado e conflito. Novos Cadernos NAEA, 15(2), 279-313. http://dx.doi.org/10.5801/ncn.v15i2.719

Pérez-Gil, L. (2001). O sistema médico Yawanáwa e seus especialistas: cura, poder e iniciação xamânica. Cadernos de Saúde Pública, 17(2), 333-344. https://doi.org/10.1590/S0102-311X2001000200008

Portela, C. A., \& Nogueira, M. C. R. (2016). Sobre indigenismo e autoria indígena no Brasil: novas epistemologias na contemporaneidade. História Unisinos, 20(2), 154-162. https:// doi.org/10.4013/htu.2016.202.04 
Porto-Gonçalves, C. W. (2005). Apresentação da edição em português. In E. Lander (Org.), A colonialidade do saber: Eurocentrismo e ciências sociais. Perspectivas latino-americanas (pp. 3-5). Perspectivas latino-americanas. CLACSO.

Quijano, A. (2002). Colonialidade, poder, globalização e democracia. Novos Rumos, 17(37), 1-25. https://doi.org/ 10.36311/0102-5864.17.v0n37.2192

Quijano, A. (2005). Colonialidade do poder, eurocentrismo e América Latina. In E. Lander (Org.), A colonialidade do saber: Eurocentrismo e ciências sociais. Perspectivas latino-americanas (pp. 107-130). Perspectivas latinoamericanas. CLACSO.

Reis, D. A., Costa, S. K. L. D., Faro, A. C. M., \& Malosso, M. G. (2016). Saúde do idoso indígena no Brasil: revisão integrativa. Revista de Enfermagem UFPE, 10(8), 3077-3089. https://ds.saudeindigena.icict.fiocruz.br/handle/bvs/1444

Ressurreição, S. B. D., \& Sampaio, S. M. D. R. (2017). Transições e reconfigurações do self de jovens indígenas na experiência universitária. Psicologia Escolar e Educacional, 21(3), 495-504. https://doi.org/ $10.1590 / 2175-35392017021311188$

Carvalho, G., \& Rosevics, L. (Orgs.). (2017). Diálogos internacionais: reflexões críticas do mundo contemporâneo. Perse.

Sandes, L. F. F., Freitas, D. A.; Souza, M. F. N. S. D., \& Leite, K. B. D. S. (2018). Atenção primária à saúde de indígenas sul-americanos: revisão integrativa da literatura. Revista Panamericana de Salud Pública, 42, 1-9. https://doi.org/ 10.26633/RPSP.2018.163

Sant'Anna, A. L. D. O., Castro, A. D. C., \& Jacó-Vilela, A. M. (2018). Ditadura militar e práticas disciplinares no controle de índios: perspectivas psicossociais no relatório figueiredo. Psicologia \& Sociedade, 30, 1-10. https://doi.org/ $10.1590 / 1807-0310 / 2018 \mathrm{v} 30188045$

Sant'Anna, A. L. D. O., Castro, A. D. C., \& Jacó-Vilela, A. M. (2019). Fragmentos históricos do índio como trabalhador rural na Psicologia do Trabalho de meados do século XX. Arquivos Brasileiros de Psicologia, 71 (3), 36-47.

Santos, A. D. O. (2019). O Enegrecimento da Psicologia: Indicações para a Formação Profissional. Psicologia: Ciência e Profissão, 39(n.spe), 159-171. https://doi.org/10.1590/1982-3703003222113

Santos, C. J. F., \& Santos, V. R. (2019). Decolonialidades indígenas. In F. A. C. Costa \& M. R, Mesquita (Orgs.), Psicologia política no Brasil e enfrentamentos a processos antidemocráticos (pp. 231-243). Edufal.

Santos, E. D., Arcanjo, N. G., Souza, A. C. S. S., Laghi, A. C. B., Soares, L. S., Costa, N. C. C. S., Esteves, A. V. F., \& Fernandes, M. V. C. (2018). A criança indígena e as causas de mortalidade: Revisão integrativa. Scientia Amazonia, 7(1), 28-36.

Scorsolini-Comin, F. (2017). Espiritualidade e brasilidade na clínica etnopsicológica. Psicologia Clínica, 29(2), 319-338.

Segato, R. L. (2003). Uma agenda de ações afirmativas para as mulheres indígenas do Brasil. Série Antropologia, N. 326. Departamento de Antropologia da Universidade de Brasília.

Simão, L. M., \& Rios, H. S. (2016). Aspectos da dialogia do mito Madre Ñame na cultura indígena wounaan-nonam. Psicologia USP, 27(2), 219-228. https:// doi.org/10.1590/0103-6564D20160005

Staliano, P., Mondardo, M. L., \& Lopes, R. C. (2019). Onde e Como se Suicidam os Guarani e Kaiowá em Mato Grosso do Sul: Confinamento, Jejuvy e Tekoha. Psicologia: Ciência e Profissão, 39(n.spe), 9-21. https://doi.org/ $10.1590 / 1982-3703003221674$

Souza, R. S. B., Oliveira, J. C., \& Teodoro, M. L. (2019). Construção de um Instrumento para Avaliar o Uso de Bebidas Alcóolicas em uma Etnia Indígena de Minas Gerais. Psicologia: Ciência e Profissão, 39, 1-11. https://doi.org/ $10.1590 / 1982-3703003176628$

Teixeira, L. C. I. (2010). Introdução. In Conselho Regional de Psicologia de São Paulo, Psicologia e Povos indígenas (pp. 7-9).

Travassos, M. D. R. D. C., \& Ceccarelli, P. R. (2016). Ritos de passagem: o lugar da adolescência nas sociedades indígenas Tembé Tenetehara e Kaxuyana. Reverso, 38(71), 99-106.

Veiga, L. M. (2019). Descolonizando a psicologia: notas para uma Psicologia Preta. Fractal: Revista de Psicologia, 31(n.spe), 244-248. https://doi.org/10.22409/1984-0292/v31i_esp/29000

Viana, I., \& Maheirie, K. (2017). Identidades em reinvenção: O Fortalecimento Coletivo de Estudantes Indígenas no Meio Universitário. Revista Polis e Psique, 7(3), 224-249.

Vitale, M. P., \& Grubits, S. (2009). Psicologia e povos indígenas: um estudo preliminar do "Estado da Arte". Revista Psicologia e Saúde, 1(1), 15-30. https://doi.org/10.20435/pssa.vli1.10 


\section{Brisana Índio do Brasil Macêdo Silva}

Graduada e Mestre em Psicologia pela Universidade Federal do Delta do Parnaíba (UFDPar), Parnaíba - PI. Brasil. Professora Substituta de Psicologia da Universidade Federal do Delta do Parnaíba (UFDPar), Parnaíba - PI. Brasil. Doutoranda em Psicologia na Universidade Federal do Ceará (UFC), Fortaleza - CE. Brasil.

E-mail: brisanaindio@gmail.com

(1) https://orcid.org/0000-0003-1150-8291

\section{João Paulo Macedo}

Doutor em Psicologia pela Universidade Federal do Rio Grande do Norte (UFRN), Natal - RN. Brasil. Professor Assistente da Universidade Federal do Delta do Parnaíba (UFDPar), Parnaíba - PI. Brasil. Vinculado ao Programa de Pós-Graduação em Psicologia e bolsista de produtividade do CNPq.

E-mail: jampamacedo@gmail.com

(1) https://orcid.org/0000-0003-4393-8501

Endereço para envio de correspondência:

Universidade Federal do Delta do Parnaíba. Av. São Sebastião, 2819, Nossa Sra. de Fátima. CEP: 64202-020.

Parnaíba - PI. Brasil.

Recebido 17/03/2019

Aceito 20/07/2020

Received $03 / 17 / 2019$

Approved 07/20/2020

Recibido 17/03/2019

Aceptado 20/07/2020

Como citar: Silva, B. Í. B. M., \& Macedo, J. P. (2021). Povos Indígenas no Brasil e a Descolonização da Psicologia. Psicologia: Ciência e Profissão, v(n), pp-pp. https://doi.org/10.1590/1982-3703003221362

How to cite: Silva, B. Í. B. M., \& Macedo, J. P. (2021). Indigenous People in Brazil and the Decolonization of Psychology. Psicologia: Ciência e Profissão, v(n), pp-pp. https://doi.org/10.1590/1982-3703003221362

Cómo citar: Silva, B. Í. B. M., \& Macedo, J. P. (2021). Los Pueblos Indígenas en Brasil y la Descolonización de la Psicología. Psicologia: Ciência e Profissão, v(n), pp-pp. https://doi.org/10.1590/1982-3703003221362 